Article

\title{
One-Step Preparation of Super-Hydrophobic Micro-Nano Dendrites on Al Alloy for Enhanced Corrosion Resistance
}

\author{
Xuewu Li ${ }^{1, *}$, Tian Shi ${ }^{1}$, Ben $\mathrm{Li}^{2}$, Chuanwei Zhang ${ }^{1}$, Bin Zhong ${ }^{1}$, Yuan $\mathrm{Lv}^{1}$ and \\ Qiaoxin Zhang ${ }^{2, *}$ \\ 1 School of Mechanical Engineering, Xi'an University of Science and Technology, 58 Yanta Road, Xi'an 710054, \\ China; tianshi@xust.edu.cn (T.S.); zhangcw@xust.edu.cn (C.Z.); zhongbin2015@xust.edu.cn (B.Z.); \\ lvyuan85@live.com (Y.L.) \\ 2 School of Mechanical and Electronic Engineering, Wuhan University of Technology, 122 Luoshi Road, \\ Wuhan 430070,China; li_dd21@163.com \\ * Correspondence: lixuewu55@126.com (X.L.); zhangqx@whut.edu.cn (Q.Z.); \\ Tel.: +86-298-558-3159 (X.L.); +86-278-785-9133 (Q.Z.)
}

Received: 1 October 2018; Accepted: 14 November 2018; Published: 17 November 2018

\begin{abstract}
Corrosion failure is a thorny issue that restricts the applications of Al alloys. As a research hotspot in functional realization, hydrophobic fabrication exactly offers an efficient method to settle metallic corrosions. This work has developed a facile and low-cost method to enhance corrosion resistance of $\mathrm{Al}$ alloys. The micro-nano dendrites have been firstly prepared on metallic substrate using one-step potentiostatic deposition. Then, wetting and electrochemical behaviors have been systematically investigated after stearic acid modification. Results show that the as-prepared surface possesses amplified and durable water repellence with an apparent contact angle (CA) of $154.2^{\circ}$ and a sliding angle (SA) of $4.7^{\circ}$. Meanwhile, owing to the trapped air in dendrites, the newly-generated solid-air-liquid interfaces help to resist seawater penetration by reducing interfacial interactions on the super-hydrophobic surface as well as significantly enhance its corrosion resistance. This work sheds positive insights into extending the applications of Al alloys in many areas, especially for ocean engineering fields.
\end{abstract}

Keywords: Al alloy; super-hydrophobic surface; deposition; corrosion resistance

\section{Introduction}

$\mathrm{Al}$ alloys have been extensively used as engineering components, parts and plates in shipbuilding and oceanic engineering areas because of their easy accessibility, good workability, high specific strength and low price [1,2]. Usually, Al alloys are easily oxidized to protect themselves from corrosion [3]. However, reactive anions can erode metallic substrates thereby leading to corrosion failures in wet conditions [4]. As a result, their service lives and application fields are seriously restricted. Hence, the study of protecting $\mathrm{Al}$ alloys from corrosion in seawater is of great economic value and practical significance.

In recent years, various methods have been developed to enhance corrosion resistances of $\mathrm{Al}$ alloys, such as corrosion inhibitor [5], mechanical alloying [6], aging process [7,8], laser treatment [9] and friction stir welding [10]. In addition, Kaseemet al. have reported an oxide film on $7075 \mathrm{Al}$ alloy with enhanced corrosion resistance in 3.5\% NaCl solution via the micro-arc oxidation process [11]. Ji et al. have prepared an alumina coating on LY12 Al alloy using micro-arc oxidation and the phosphate process for improved corrosion resistance in seawater [12]. However, phosphate technology and the coatings with heavy metal ions are contaminative. Laser treatment is usually uncontrollable. 
Some other methods may be complicated and costly. Hence, it is still a big challenge to develop facile, low-cost and environment-friendly anticorrosion methods for $\mathrm{Al}$ alloys.

Inspired by the water-repelling and self-cleaning instincts of lotus leaves [13,14], preparing super-hydrophobic layers on $\mathrm{Al}$ alloys can reduce interfacial interactions with corrosive mediums in seawater, thereby postponing their corrosion rates. Usually, high stability of Cassie wetting state as well as high apparent contact angle and low sliding angle are necessary for a super-hydrophobic surface [15,16]. In recent years, various methods have been reported to fabricate super-hydrophobic Al alloys, such as chemical etching [17], in suit polymerization [18], sol-gel process [19], grinding technique [20], laser process [21] and spraying technique [22]. In addition, $\mathrm{Wu}$ et al. have prepared a super-hydrophobic $2024 \mathrm{Al}$ alloy with excellent water repellence using chemical etching and anodic oxidation [23]. Wei et al. have fabricated a super-hydrophobic Al alloy via multi-step etching, electro-deposition and modification processes [24]. Li et al. have reported a super-hydrophobic $\mathrm{Al}$ sheet with three steps including etching, replacement deposition and annealingtreatment [25]. However, the corrosion resistances in seawater are seldom investigated in the works above. In addition, some super-hydrophobic processes are carried out under poor and complicated conditions.

Herein, a low-cost and facile approach is developed to fabricate multifunctional $\mathrm{Al}$ alloys' surfaces. Firstly, micro-nano dendrites have been prepared on $\mathrm{Al}$ alloy surface with one-step potentiostatic deposition. After stearic acid modification of rough structures, a super-hydrophobic surface is attained. Finally, its corrosion resistance in seawater is evaluated via electrochemical tests. The resultant surface contributes to reduce interfacial interactions with corrosive mediums induced by the newly-generated solid-air-liquid interfaces. This work sheds positive insights into broadening applications of $\mathrm{Al}$ alloys especially in oceanic areas.

\section{Materials and Methods}

\subsection{Materials}

The commercially available $5005 \mathrm{Al}$ alloys plates $(10 \mathrm{~mm} \times 10 \mathrm{~mm} \times 2 \mathrm{~mm})$ with compositions of 97.0 wt. \% Al, 1.5 wt. \% Mg, 0.7 wt. \% Fe, 0.2 wt. \% Mn, 0.2 wt. \% Zn, 0.2 wt. \% Cu, 0.1 wt. \% $\mathrm{Si}$ and $0.1 \mathrm{wt.} \% \mathrm{Cr}$ were purchased from Shanghai Haocheng Metal Co., Ltd., China. Stearic acid (STA, $>96 \%$ ), silver nitrate (AR, $\geq 99.8 \%$ ) and ethanol absolute (AR) were obtained from Sinopharm Chemical Reagent Co., Ltd., Shanghai, China. Deionized (DI) water was made from a millipore water purification system (MilliQ, specific resistivity $>18 \mathrm{M} \Omega \cdot \mathrm{cm}$, S.A., Molsheim, France).

\subsection{Preparation}

$\mathrm{Al}$ alloys were sequentially polished with $\mathrm{W} 40, \mathrm{~W} 10$ and W3.5 sandpapers before ultrasonically cleaning in ethanol and DI water. After that, potentiostatic deposition was conducted in $20 \mathrm{mM}$ silver nitrate solution at $-0.50 \mathrm{~V}$ for $90 \mathrm{~s}$ using an electrochemical workstation (CHI660D, Chenhua Instrument Co., Ltd., Shanghai, China) equipped with a standard three-electrode system (the prepared sample as a working electrode, the saturated calomel electrode as a reference electrode and the Pt net as a counter electrode). Then, the as-prepared samples were dried with high pure nitrogen and surface modification was executed by immersing them into ethanol-water solution (volume ratio of 1:1) of $10 \mathrm{mM} \mathrm{STA}$ for $12 \mathrm{~h}$. Finally, the resultant samples werecleanedand dried in air for use.

\subsection{Characterization}

Environmental Scanning Electron Microscopy (FESEM, FEI Quanta200 FEG, Hillsboro, OR, USA) and Energy Dispersive X-ray Spectrometer (EDX, Oxford Instruments Inca X-Max, Oxfordshire, UK) were used to characterize morphologies andcompositions. X-ray diffraction (XRD) analysis was conducted to determine crystal structures using a D8 Advance Diffract Meter (Bruker, Karlsruhe, Germany) at $40 \mathrm{kV}$. Contact Angle Meter (OCA20, Dataphysics GmbH, Filderstadt, Germany) was 
used to assess the wettability by using water droplets $(4 \mu \mathrm{L})$. An electrochemical workstation (CHI660D, Chenhua Instrument Co., Ltd., Shanghai, China) equipped with a standard three-electrode system (exposing area of $1 \mathrm{~cm}^{2}$ for aworking electrode) was used to evaluate corrosion resistance in $3.5 \mathrm{wt}$. \% $\mathrm{NaCl}$ solution. Polarization curve was recorded from -1400 to $-400 \mathrm{mV}$ with a scanning rate of $1 \mathrm{mV} / \mathrm{s}$. Electrochemical impedance spectroscope (EIS) was tested between $10 \mathrm{mHz}$ and $100 \mathrm{kHz}$ with a sine wave amplitude of $10 \mathrm{mV}$. Before tests, electrodes were immersed into electrolyte for $0.5 \mathrm{~h}$ to achieve steady states. The consistency analysis of polarization test was conducted with three samples for each preparation.

\section{Results and Discussion}

\subsection{Structure Characterization}

SEM images of the deposited Al alloy surfaces at various magnifications are shown in Figure 1a-c. Clearly, uniformly dispersed micro-nano dendrites form on sample with average trunk length of $15 \mu \mathrm{m}$ (Figure 1b) and sub-branch dimension of $500 \mathrm{~nm}$ (Figure 1c). The formation of dendrites on $\mathrm{Al}$ alloy surfacelies on the deposition process (Figure 1d). Firstly, sporadic nucleation sites with silver buds gradually take shapes induced by the reduction reaction in silver nitrate solution. Then, nucleation tips with low energy promote sustained buds attachment thereby aggregating nuclei to form trunks, branches and sub-br-anches. As reduction, nucleation, adsorption and aggregation continue, the resultant dendrites grow rapidly on $\mathrm{Al}$ alloy surface.
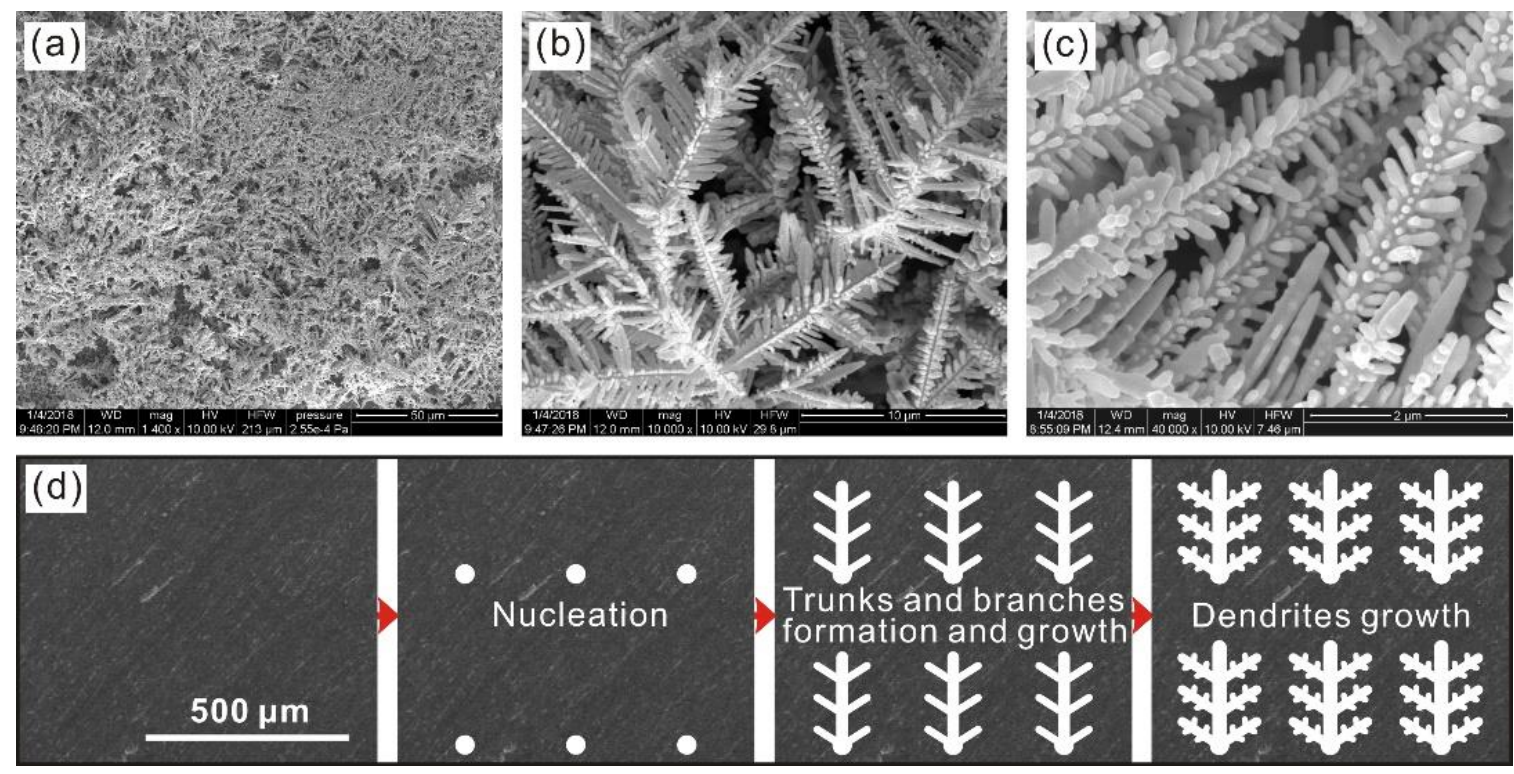

Figure 1. (a-c) SEM images of deposited Al alloys; (d) the growth process diagram of dendrites on $\mathrm{Al}$ alloy substrate.

To gain insights into the deposited surface, EDX and mapping analysesare conducted and the results are shown in Figure 2a. Clearly, $\mathrm{Al}$ alloy is mainly composed of $\mathrm{Al}, \mathrm{Mg}$ and $\mathrm{O}$ implying the existence of metallic oxides on substrate. In addition, $\mathrm{Ag}$ elements $(\mathrm{L} \alpha=2.98 \mathrm{keV}, \mathrm{L} \beta=3.20 \mathrm{keV}$, $\mathrm{L} \gamma=3.52 \mathrm{keV}, \mathrm{Ll}=2.63 \mathrm{keV}$ ) are observed, which come from the micro-nano dendrites prepared in such deposition process. XRD analysis is also carried out to determine crystal structures of dendrites deposited on Al alloy, as seen in Figure $2 \mathrm{~b}$. The characteristic peaks at $38.4^{\circ}, 46.5^{\circ}, 65.0^{\circ}, 77.4^{\circ}$ and $81.3^{\circ}$ are indexed as (111), (200), (220), (311) and (222) crystal planes indicating the face-centered cubic structures of silver dendrites (JCPDS file No. 4-783). Meanwhile, the broadening background diffractions and characteristic peak at $22.0^{\circ}$ result from the aluminum oxide membrane on $\mathrm{Al}$ alloy substrate [26]. 

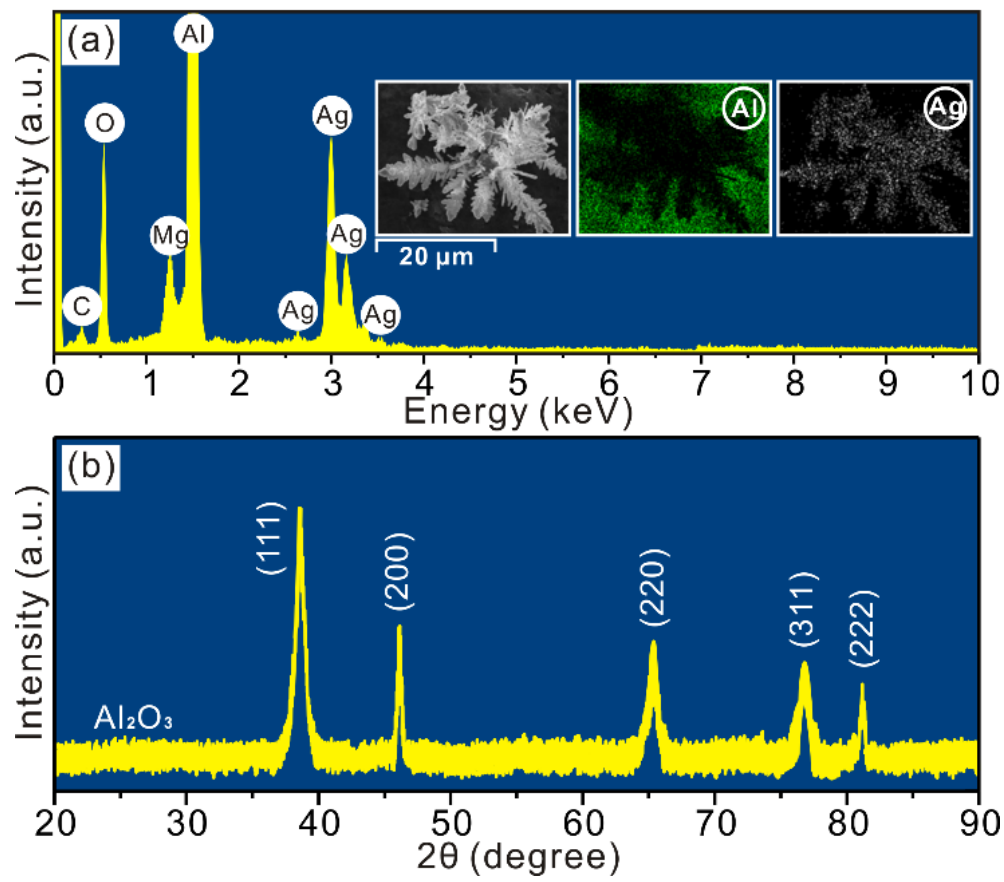

Figure 2. (a) EDX, mapping and (b) XRD analyses of deposited surface.

\subsection{Wettability Characterization}

Wet abilities of $\mathrm{Al}$ alloy substrate are analyzed in Figure 3a,b. Clearly, a hydrophilic substrate is observed. After STA modification of Al alloy substrate (modified substrate), a hydrophobic CA of $90.8^{\circ}$ is achieved (Figure 3c). However, after STA modification of the deposited Al alloy sample (modified deposited sample), a super-hydrophobic CA $\left(>150.0^{\circ}\right)$ of $154.2^{\circ}$ is attained (Figure 3e). SA is another indispensable parameter for assessing wettabilities [27]. As seen, the droplet still adheres to modified substrate even when it tilts to $90.0^{\circ}$ suggesting a strong adhesion to liquid (Figure $3 \mathrm{~d}$ ). However, for the modified deposited sample, a super-hydrophobic SA $\left(<10.0^{\circ}\right)$ of $4.7^{\circ}$ is achieved, thereby displaying excellent water repellence (Figure 3f).
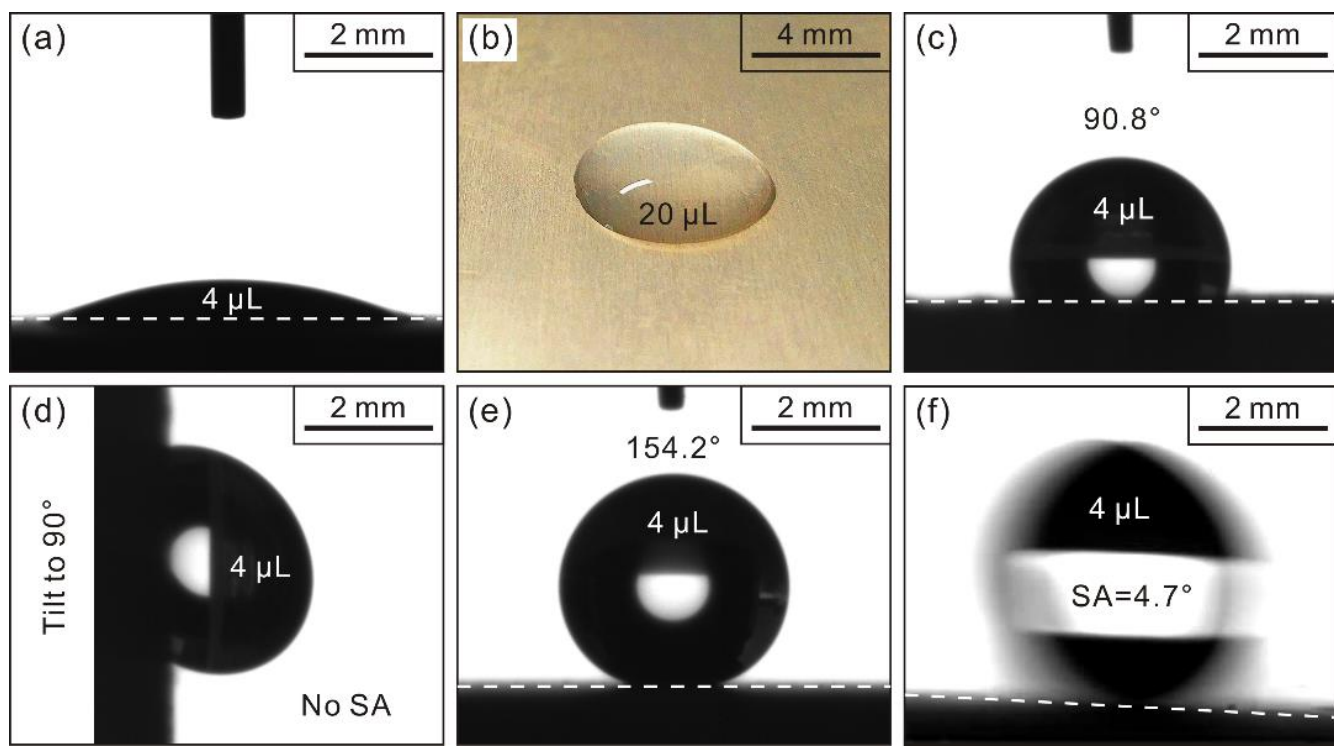

Figure 3. Apparent contact angles of (a) Al alloy substrate; (c) modified substrate; and (e) modified deposited sample; (b) optical photo of a drop $(20 \mu \mathrm{L})$ on Al alloy substrate. Sliding angles of (d) modified substrate and (f) modified deposited sample. 
For Al alloy substrate, water easily wets a metallic surface suggesting a solid-liquid interface (Figure 3a,b). However, for modified deposited surface, super-hydrophobic behavior is attained indicating the Cassie-Baxter wetting model [28]. In such state, modified dendrites help to trap air when contacting with liquid leading to the formation of solid-air-liquid interfaces (Figure 4a), which can be quantitatively clarified in the Cassie-Baxter equation [28]:

$$
\cos \mathrm{CA}=f_{1} \cos \theta-f_{2}\left(f_{1}+f_{2}=1\right)
$$

where $\theta$ represents the intrinsic contact angle $\left(90.8^{\circ}\right), f_{1}$ and $f_{2}$ refers to the proportions of a droplet contacting with as-prepared surface and air, respectively. This equation reveals that, for modified deposited sample, the super-hydrophobic CA of $154.2^{\circ}$ signifies a droplet $90.0 \%$ making contact with air, thereby looking like a spherical droplet standing on as-prepared surface (Figure $4 \mathrm{~b}$ ). Hence, the wettability has been prepared from hydrophilicity to super-hydrophobicity by depositing micro-nano dendrites on $\mathrm{Al}$ alloy surface. In addition, the high stability of Cassie wetting state resulting from its durable super-hydrophobicity is also achieved for a modified deposited sample (Figure 4c).
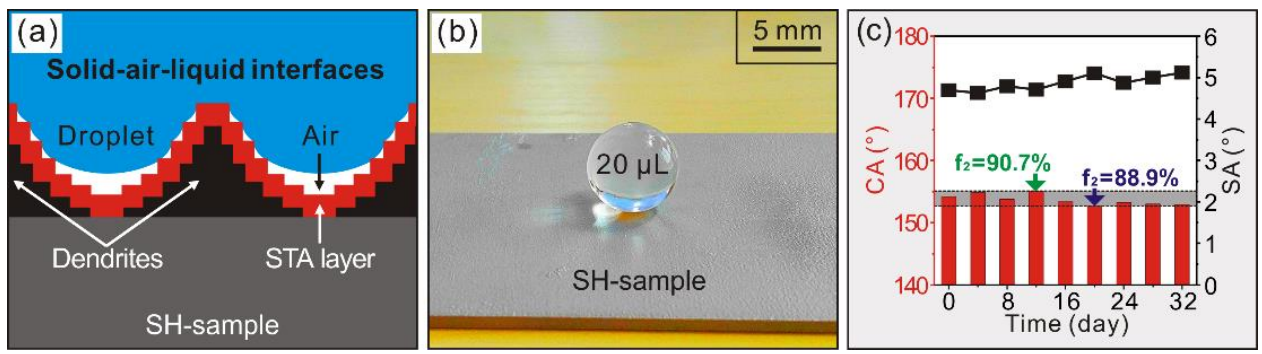

Figure 4. (a) Interfacial relationships of modified deposited sample (SH-sample); (b) optical photo of a drop on SH-sample; (c) effectof exposure time in air onthe wettability of the SH-sample.

\subsection{Anticorrosion Characterization}

The corrosion resistances of as-prepared samples are characterized by potentiodynamic polarization curves in Figure 5a. Generally, a surface with low corrosion current density and positive-shifting corrosion potential can gain superior anticorrosion ability [29]. After fitting with the Tafel extrapolation method, current densities for substrate, modified substrate and modified deposited sample are achieved with $2.90,1.62$ and $0.66 \mu \mathrm{A} / \mathrm{cm}^{2}$, respectively. Meanwhile, corrosion potentials shift positively from $-1.15,-0.97$ to $-0.83 \mathrm{~V}$ for the samples above. These data indicate that the modified deposited sample possesses superior corrosion resistance, followed by modified substrate and then Al alloy substrate. Meanwhile, good consistency of polarization tests is also achieved for as-prepared samples (Figure 5b).
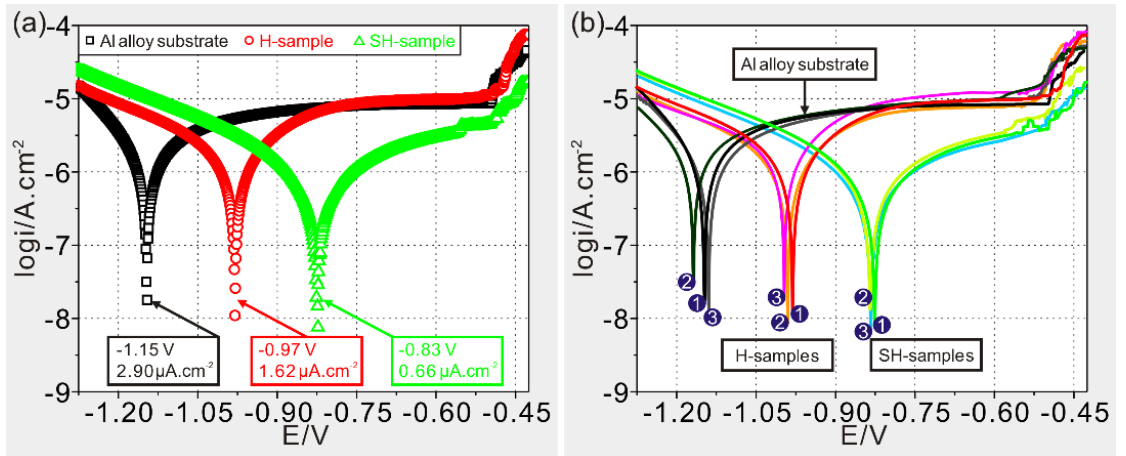

Figure 5. (a) Potentiodynamic polarization curves of Al alloy substrate, modified substrate (H-sample) and modified deposited sample (SH-sample); (b) consistency analysis of polarization tests for various samples. 
EIS analyses are also used to assess their corrosion resistances and the resultant Nyquist plots are shown in Figure 6. In a Nyquist plot, a big capacitive reactance arcsignifies a better hindrance of capacitance to charge transfers, which also suggests a superior corrosion resistance [29]. As seen, the capacitive reactance arc for a modified deposited sample is larger than others, and the same goes for anticorrosion ability. Hence, the same trend about corrosion resistance displayed in the polarization curve coincides well with EIS results.

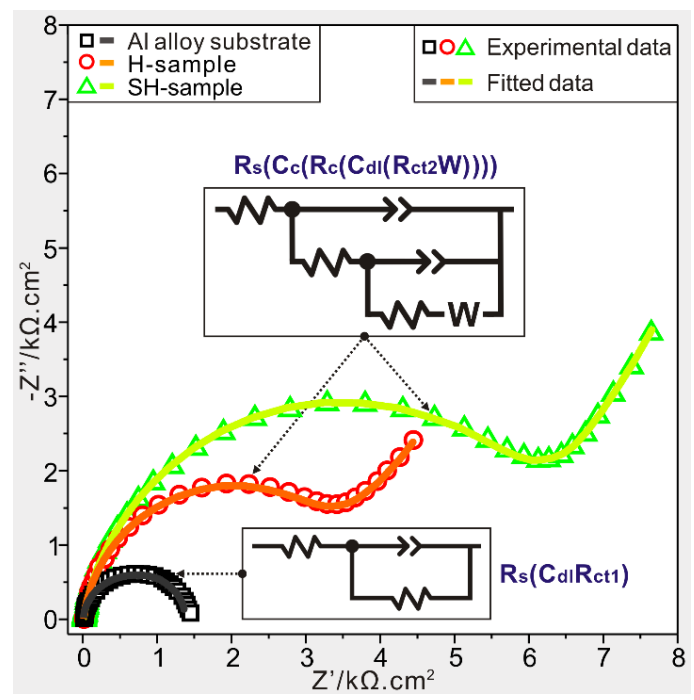

Figure 6. Nyquist plots of Al alloy substrate, modified substrate (H-sample) and modified deposited sample (SH-sample). The inserts referring to equivalent circuit patterns of the substrate and modified samples.

To obtain electrochemical data of as-prepared samples, ZSimDemo software (3.20, Chenhua Instrument Co., Ltd., Shanghai, China) is used to fit EIS plots. After fittings, the circuit pattern $R_{\mathrm{S}}\left(C_{\mathrm{dl}} R_{\mathrm{ct} 1}\right)$ in Figure 6 is found suitable to fit the EIS curve of $\mathrm{Al}$ alloy substrate in seawater. In this model, $R_{\mathrm{s}}, C_{\mathrm{dl}}$ and $R_{\mathrm{ct} 1}$ represent solution resistance, double-layer capacitance and charge-transfer resistance, respectively. The pattern $R_{\mathrm{S}}\left(C_{\mathrm{c}}\left(R_{\mathrm{C}}\left(C_{\mathrm{dl}}\left(R_{\mathrm{ct} 2} W\right)\right)\right)\right)$ in Figure 6 is found to be appropriate to equate electrochemical processes of modified samples (including modified substrate and modified deposited sample), where $C_{\mathrm{c}}$ and $R_{\mathrm{c}}$ respectively refer to capacitance and resistance ofmodified films. Diffusion impedance $(W)$ is used to characterize the inhibitory ability ofthe diffusion process from solution to electrode surface. In an electrode process, $C_{c}$ and $C_{d l}$ are concerned with constant phase elements (CPE) for characterizing capacitances. After fittings, the electrochemical data areachieved in Table 1. As seen, small fitting errorsare observed, whichfurther demonstrates the reasonable fittings of experimental EIS results. After comparison and analysis, the modified deposited sample gains the maximum impedance and minimum capacitance suggesting greatly improved corrosion resistance.

Table 1. Fitted electrochemical parameters ( $\Delta$ referring to fitting error) of $\mathrm{Al}$ alloy substrate (Sample 1 ), modified substrate (Sample 2) and modified deposited sample (Sample 3).

\begin{tabular}{|c|c|c|c|c|c|c|c|c|c|c|c|c|}
\hline Sample & $\begin{array}{c}R_{\mathrm{s}} \\
\left(\Omega \cdot \mathrm{cm}^{2}\right)\end{array}$ & $\begin{array}{c}\Delta \\
(\%)\end{array}$ & $\begin{array}{c}R_{\mathrm{ct}} \\
\left(\Omega \cdot \mathrm{cm}^{2}\right)\end{array}$ & $\begin{array}{c}\Delta \\
(\%)\end{array}$ & $\begin{array}{c}R_{\mathrm{c}} \\
\left(\Omega \cdot \mathrm{cm}^{2}\right)\end{array}$ & $\begin{array}{c}\Delta \\
(\%)\end{array}$ & $\begin{array}{c}W \\
\left(\Omega \cdot \mathrm{cm}^{2}\right)\end{array}$ & $\begin{array}{c}\Delta \\
(\%)\end{array}$ & $\begin{array}{c}Y_{\mathrm{dl}} \\
\left(\mu \mathrm{F} \cdot \mathrm{cm}^{-2}\right)\end{array}$ & $\begin{array}{c}\Delta \\
(\%)\end{array}$ & $\begin{array}{c}Y_{c} \\
\left(\mu \mathrm{F} \cdot \mathrm{cm}^{-2}\right)\end{array}$ & $\begin{array}{c}\Delta \\
(\%)\end{array}$ \\
\hline 1 & 11 & 1.2 & 1428 & 2.5 & - & - & - & - & 61.7 & 3.4 & - & - \\
\hline 2 & 8 & 3.3 & 3306 & 1.9 & 331 & 3.8 & 0.008 & 5.3 & 15.2 & 4.6 & 21.9 & 2.3 \\
\hline 3 & 10 & 0.8 & 6374 & 1.7 & 390 & 5.5 & 0.025 & 7.0 & 4.2 & 8.3 & 3.8 & 6.1 \\
\hline
\end{tabular}

$\mathrm{Al}$ alloy substrate displays poor corrosion resistance. This is a result of the reactive anions in seawater, which directly corrodesthe substrate, thus leading to metallic failures (Figure 7a). After STA modification of substrate, the corrosion resistance has been greatly improved. This is due to the STA layer, which exactly hinders seawater penetrations by impeding interfacial interactions between 
corrosive ions and Al alloy substrate (Figure 7b). However, for the modified deposited sample, the corrosion resistance is further enhanced. This is not only because of the assembled STA layer. On the other hand, the as-prepared super-hydrophobic dendrites help to improve the chance for trapping air (Figure 7c). The air phase can serve as dielectric for a parallel plate capacitor, which exactly keeps the electrons from transferring between seawater and sample. Based on these, the Al alloy has been prepared with greatly enhanced corrosion resistance in seawater with deposition and modification processes in this work.
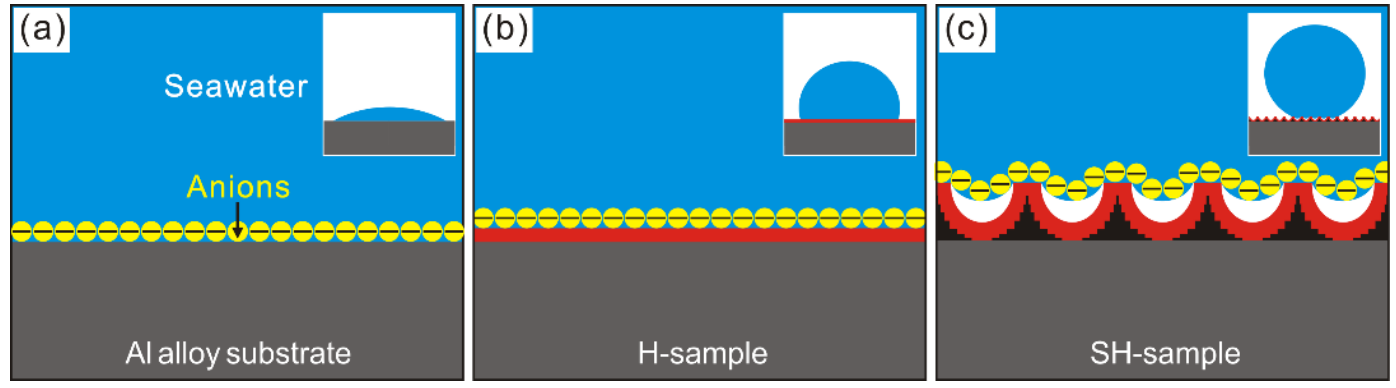

Figure 7. Interfacial relationships of (a) Al alloy substrate, (b) modified substrate (H-sample) and (c) modified deposited sample (SH-sample).

The stabilities of wettabilities and corrosion resistances in seawater are investigated for modified deposited sample, as shown in Figure 8. Clearly, after 20 days of immersion, both apparent contact angles (Figure 8a) and corrosion current densities (Figure 8b) are maintained at relatively stable levels, suggesting excellent durability in seawater. Hence, the durable corrosion resistance of the as-prepared Al alloy resulting from its super-hydrophobic stability is achieved to expand its potential applications as engineering materials in extreme environments.
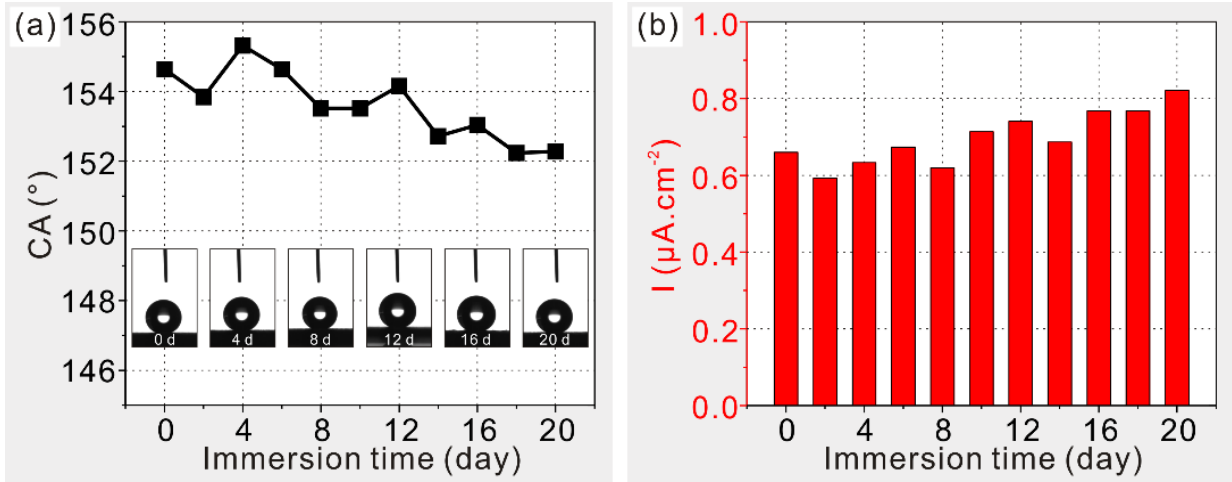

Figure 8. Effects of immersion time in seawater on (a) wettabilities and (b) corrosion resistances of the modified deposited sample.

\section{Conclusions}

(1) Uniformly dispersed micro-nano dendrites have been fabricated on $5005 \mathrm{Al}$ alloy surface using a facile potentiostatic deposition treatment.

(2) After stearic acid modification, the as-prepared dendrites have displayed greatly amplified and durable water repellence with super-hydrophobic apparent contact angle of $154.2^{\circ}$ and sliding angle of $4.7^{\circ}$.

(3) The Super-hydrophobic Al alloy surface has been prepared with greatly enhanced corrosion resistance in seawater by reducing interfacial interactions between corrosive ions and modified deposited surface, owing to the newly-generated composite solid-air-liquid interfaces. 
Author Contributions: Q.Z. and X.L. conceived and designed the experiments. T.S., C.Z. and Y.L. performed the experiments. B.L. and B.Z. wrote the manuscript. All authors analyzed the data, checked the article and contributed to the interpretation of the results. X.L., T.S., C.Z. and Y.L. revised the manuscript.

Funding: The work is financially supported by the National Natural Science Foundation of China (No. 51875425, 51705416, 51804251) and the Natural Science Basic Research Plan in the Shanxi Province of China (No.2016JQ5054).

Acknowledgments: We would like to thank Chen Zhou and Dong Yu (Analytical and Testing Center, WHUT) for help in SEM observation and EDX analysis.

Conflicts of Interest: The authors declare no competing financial interest.

\section{References}

1. Seikh, A.H.; Baig, M.; Ammar, H.R.; Alam, M.A. The influence of transition metals addition on the corrosion resistance of nanocrystalline $\mathrm{Al}$ alloys produced by mechanical alloying. Metals 2016, 6, 140. [CrossRef]

2. Wan, H.L.; Lin, J.P.; Min, J.Y. Effect of laser ablation treatment on corrosion resistance of adhesive-bonded Al alloy joints. Surf. Coat. Technol. 2018, 345, 13-21. [CrossRef]

3. Ou, J.F.; Fang, X.Z.; Zhao, W.J.; Lei, S.; Xue, M.S.; Wang, F.J.; Li, C.Q.; Lu, Y.L.; Li, W. Influence of hydrostatic pressure on corrosion behavior of superhydrophobic surfaces on bare and oxidized aluminum substrates. Langmuir 2018, 34, 5807-5812. [CrossRef] [PubMed]

4. Olajire, A.A. Recent advances on organic coating system technologies for corrosion protection of offshore metallic structures. J. Mol. Liq. 2018, 269, 572-606. [CrossRef]

5. Li, J.C.; Dang, J. A Summary of corrosion properties of Al-rich solid solution and secondary phase particles in $\mathrm{Al}$ alloys. Metals 2017, 7, 84. [CrossRef]

6. Liu, X.Y.; Wang, Z.P.; Fu, B.G.; Long, L.; Zhang, X.L.; Cui, H.X. Effects of Mg content on the mechanical properties and corrosion resistance of Al-Cu-Mg-Ag alloy. J. Alloy. Compd. 2016, 685, 209-215. [CrossRef]

7. Xu, Y.Q.; Zhan, L.H. Effect of creep aging process on microstructures and properties of the retrogressed Al-Zn-Mg-Cu alloy. Metals 2016, 6, 189. [CrossRef]

8. Qi, H.; Liu, X.Y.; Liang, S.X.; Zhang, X.L.; Cui, H.X.; Zheng, L.Y.; Gao, F.; Chen, Q.H. Mechanical properties and corrosion resistance of $\mathrm{Al}-\mathrm{Cu}-\mathrm{Mg}-\mathrm{Ag}$ heat-resistant alloy modified by interrupted aging. J. Alloy. Compd. 2016, 657, 318-324. [CrossRef]

9. Yang, Y.; Chen, Y.; Zhang, J.X.; Gu, X.H.; Qin, P.; Dai, N.W.; Li, X.P.; Kruth, J.P.; Zhang, L.C. Improved corrosion behavior of ultrafine-grained eutectic Al-12Si alloy produced by selective laser melting. Mater. Des. 2018, 146, 239-248. [CrossRef]

10. Fouladi, S.; Ghasemi, A.H.; Abbasi, M.; Abedini, M.; Khorasani, A.M.; Gibson, I. The effect of vibration during friction stir welding on corrosion behavior, mechanical properties, and machining characteristics of stir zone. Metals 2017, 7, 421. [CrossRef]

11. Kaseem, M.; Lee, Y.H.; Ko, Y.G. Incorporation of $\mathrm{MoO}_{2}$, and $\mathrm{ZrO}_{2}$, particles into the oxide film formed on $7075 \mathrm{Al}$ alloy via micro-arc oxidation. Mater. Lett. 2016, 182, 260-263. [CrossRef]

12. Ji, S.P.; Weng, Y.C.; Wu, Z.Z.; Ma, Z.Y.; Tian, X.B.; Fu, R.K.Y.; Lin, H.; Wu, G.S.; Chu, P.K.; Pan, F. Excellent corrosion resistance of $\mathrm{P}$ and Fe modified micro-arc oxidation coating on Al alloy. J. Alloy. Compd. 2017, 710, 452-459. [CrossRef]

13. Watson, G.S.; Green, D.W.; Cribb, B.W.; Brown, C.L.; Meritt, C.R.; Tobin, M.J.; Vongsvivut, J.; Sun, M.X.; Liang, A.P.; Watson, J.A. Insect analogue to the lotus leaf: A planthopper wing membrane incorporating a low-adhesion, nonwetting, superhydrophobic, bactericidal, and biocompatible surface. ACS Appl. Mater. Interfaces 2017, 9, 24381. [CrossRef] [PubMed]

14. Frankiewicz, C.; Attinger, D. Texture and wettability of metallic lotus leaves. Nanoscale 2016, 8, 3982-3990. [CrossRef] [PubMed]

15. Marmur, A.; Volpe, C.D.; Siboni, S.; Amirfazli, A.; Drelich, J.W. Contact angles and wettability: Towards common and accurate terminology. Surf. Innov. 2017, 5, 1-24. [CrossRef]

16. Nosonovsky, M. Multiscale roughness and stability of superhydrophobic biomimetic interfaces. Langmuir 2007, 23, 3157-3161. [CrossRef] [PubMed]

17. Shi, T.; Kong, J.Y.; Wang, X.D.; Li, X.W. Preparation of multifunctional Al-Mg alloy surface with hierarchical micro/nanostructures by selective chemical etching processes. Appl. Surf. Sci. 2016, 389, 335-343. [CrossRef] 
18. Xiao, X.; Xie, W.; Ye, Z. Preparation of corrosion-resisting superhydrophobic surface on aluminium substrate. Surf. Eng. 2018, 1-7. [CrossRef]

19. Lee, J.W.; Hwang, W. Exploiting the silicon content of aluminum alloys to create a superhydrophobic surface using the sol-gel process. Mater. Lett. 2016, 168, 83-85. [CrossRef]

20. Yu, H.D.; Zhang, X.R.; Wan, Y.L.; Xu, J.K.; Yu, Z.J.; Li, Y.Q. Superhydrophobic surface prepared by micromilling and grinding on aluminium alloy. Surf. Eng. 2016, 32, 108-113. [CrossRef]

21. Boinovich, L.B.; Modin, E.B.; Sayfutdinova, A.R.; Emelyanenko, K.A.; Vasiliev, A.L.; Emelyanenko, A.M. Combination of functional nanoengineering and nanosecond laser texturing for design of superhydrophobic aluminum alloy with exceptional mechanical and chemical properties. ACS Nano 2017, 11, 10113. [CrossRef] [PubMed]

22. Anitha, C.; Azim, S.S.; Mayavan, S. Salvinia inspired fluroine free superhydrophobic coatings. Appl. Surf. Sci. 2018, 449, 250-260.

23. Wu, Y.H.; Zhao, W.J.; Wang, W.R.; Sui, W.J. Fabricating binary anti-corrosion structures containing superhydrophobic surfaces and sturdy barrier layers for Al alloys. RSC Adv. 2016, 6, 5100-5110. [CrossRef]

24. Wei, Z.B.; Jiang, D.Y.; Chen, J.; Guo, X.G. Combination of chemical etching and electrophoretic deposition for the fabrication of multi-scale superhydrophobic Al films. Mater. Lett. 2017, 196, 115-118. [CrossRef]

25. Li, J.Y.; Lu, S.X.; Xu, W.G.; He, G.; Yu, T.L.; Cheng, Y.Y.; Wu, B. Fabrication of stable $\mathrm{Ni}_{-}-\mathrm{Al}_{4} \mathrm{Ni}_{3}-\mathrm{Al}_{2} \mathrm{O}_{3}$ superhydrophobic surface on aluminum substrate for self-cleaning, anti-corrosive and catalytic performance. J. Mater. Sci. 2018, 53, 1097-1109. [CrossRef]

26. Saravanan, G.; Mohan, S. Formation of silver nanorod arrays in an anodised aluminium oxide membrane. Trans. IMF 2015, 93, 248-254. [CrossRef]

27. Sasaki, K.; Tenjimbayashi, M.; Manabe, K.; Shiratori, S. Asymmetric superhydrophobic/superhydrophilic cotton fabrics designed by spraying polymer and nanoparticles. ACS Appl. Mater. Interfaces 2016, 8, 651-659. [CrossRef] [PubMed]

28. Zhang, X.; Zhu, W.Z.; He, G.J.; Zhang, P.Y.; Zhang, Z.J.; Parkin, I.P. Flexible and mechanically robust superhydrophobic silicone surfaces with stable Cassie-Baxter state. J. Mater. Chem. A 2016, 4, 14180-14186. [CrossRef]

29. Li, X.W.; Shi, T.; Liu, C.; Zhang, Q.X.; Huang, X.J. Multifunctional substrate of Al alloy based on general hierarchical micro/nanostructures: Superamphiphobicity and enhanced corrosion resistance. Sci. Rep. 2016, 6, 35940. [CrossRef] [PubMed] 